\title{
Changing patterns of social media use? A population-level study of Finland
}

\author{
Ilkka Koiranen ${ }^{1} \cdot$ Teo Keipi $^{1}{ }^{\mathbb{C}} \cdot$ Aki Koivula $^{1} \cdot$ Pekka Räsänen ${ }^{1}$
}

Published online: 5 June 2019

(c) The Author(s) 2019

\begin{abstract}
This article examines the changing patterns of Finnish social media use during the years 2008-2016. This is the first temporal look at changes in Finnish social media use with representative population-level data. We assess how social media use has evolved between socio-economic and demographic groups in advanced information societies, with a focus on Finland. We also look at how demographic factors associate with use purposes of social media. The target of empirical analysis is on social media use and use purposes by gender, age, education level and area of residence. The data come from nationally representative and temporally comparable surveys focusing on adult populations. Findings show that the effect of sociodemographic factors on overall use and different use purposes of social media persists. Furthermore, the results seem to show a diminishing of the socializing impact of social media; on the other hand, individual, commercial and goal-oriented use practices seem to have become a major focus of social media use.
\end{abstract}

Keywords Internet $\cdot$ Social media $\cdot$ Finland $\cdot$ Digital divides $\cdot$ Digitalization

\section{Introduction}

Social media platforms have become some of the most significant interactional tools in the Western world, made up of a number of popular platforms such as Facebook, YouTube, Twitter and Instagram. Together, these various platforms have vastly improved communication and interaction, involving both access and scope, of its users. Increasingly, social media interaction is carried out through personal technological devices that continue to increase in user convenience $[4,56,57]$. At the same time, the quantity of available content has exploded, and as such, consumers have an immense array of media material from which to choose according to personal preferences [32].

However, despite the growth of social media in terms of its provision of information, communication and interactional potential, these positive effects have not been evenly distributed among different population groups. Due to this uneven distribution in access, social media use and its benefits are divided unequally in society. For example, the elderly

Ilkka Koiranen

ilalko@utu.fi

1 Economic Sociology Unit, Department of Social Research, University of Turku, 20500 Turku, Finland and the less educated are less benefitted from social media than others (e.g. [33, 45, 47]). Indeed, studies have shown that structural differences within societal systems are mirrored in the use of the Internet and its various platforms (see [52]). As such, a general trend in technology availability may not translate to equal adoption due to issues of access, for example, resulting in a digital inequality of sorts.

After the popularity and the importance of social media in everyday life exploded, social media has become embedded in all areas of public life [51]. Social media is used not only for social interaction, but also to promote one's career, participate in political and civic domains and leverage consumption goals. In this sense, diversification of different use purposes on social media is revealing how these online social spaces have become politicized [1], commercialized $[12,56]$ and individualized [31] to a great degree. In this respect, these online social spaces are far from being neutral for everyone [51]. Different actors—such as ordinary users of various socio-demographic backgrounds within a given population, corporations, organizations, political movements and the platforms themselves - are pursuing a wide range of economic and societal benefits from their use.

These different aspects of social media have gained an important position in people's lives, although they are not distributed evenly between different population groups. 
According to earlier research, while inequality in online access has begun to decrease, use purposes and navigation competence remain a source of division societally [50]. Social media usage habits can tell a great deal about technological inequality in nations such as Finland where technology use trends are set [53]. As such, links between demographic factors and social media usage, in addition to a look into how usage has evolved during the past decade in an ever-changing online landscape, can offer valuable insight into societal Internet usage patterns and possible disparities therein.

In this article, we examine the changing patterns of Finnish social media use over recent years by concentrating on ordinary users of social media, namely Finns of various socio-demographic backgrounds throughout the population. We are especially interested in how users-in the roles of citizens and consumers - use social media in general and for varied purposes. We are also interested in how general use and different use purposes have changed in various population groups making up the ordinary user sample during the current decade. Through these analyses we are able to locate how the benefits gained from using social media have been distributed between population groups and evaluate how fundamental changes, namely politicization, commercialization and individualization in the social media sphere, have reflected to different ways to use social media. Finally, the analysis allows for a new look at inequality in digitalization, namely in terms of digital divides, in terms of primary and secondary effects among population groups.

We begin with an assessment of how social media use has evolved between the years 2008 and 2016. The target of analysis here is on social media use over participants' most recent past three-month period at the time of the survey according to gender, age, education level and area of residence. After this, we analyse how various use purposes differ among these socio-demographic groups in the years 2012 and 2016. Our empirical data come from nationally representative and temporally comparable Statistic Finland's annual surveys focusing on adult populations.

\section{Diversification of social media}

Originally, social media platforms were designed primarily for social interaction and connectedness [51]. Through these novel platforms, people were able to connect with their family members, friends, colleagues and form entirely new relationships. These features made social networking sites special originally. Alongside social media's prime feature, the social interaction aspect, multiple aspects of public life were later embedded into these new social spaces [51]. These aspects have been noticed in earlier literature, and there have been some theoretical discussion and research concerning the commercialization of social media [12, 21, 56], politicization of social media [1, 54] and social media use habits connected to individualization of social life [51, 57].

Nowadays people are presenting themselves through multiple platforms, where users can modify their presence and image while communicating with others about their interests, values and views [24]. While social interaction and connectivity were the key purposes of social media platforms in the first place, these personal actions induced by the mediation of social life are also increasing individualized behaviour on these novel social spaces.

In this sense, these new purposes, motivations and goals derived by vast changes in the online social space have not replaced social interaction, but have rather been realized through these interactions. Networks constituted on these platforms are utilized for various goal-oriented purposes, such as the endorsement of one's career [2], improvement of one's societal position through participation [1], and for example to gain status or build an image within one's social circle [18]. Arguably, social interaction remains the main purpose for SNS use, though instrumental purposes have taken hold through that central phenomenon.

The power of networks to act as mediating factors for gaining societal and economic benefits has been widely noticed in earlier literature. Granovetter [13] embraced the importance of weak ties already in the early 1970s, which are particularly prominent on social media due to easy access to others. Here, weak ties are formed with people outside a person's close circle, and these ties can be utilized to gain different kinds of benefits. Accordingly, social media has had an enormous effect on how weak ties can be formed and utilized. In this sense, it can be argued that different benefit-seeking purposes on social media are, in particular, mixed with social interaction and connectedness, while also combined with previously impossible levels of social access.

While online social spaces have been individualized, commercialized and politicized, these social spaces have been modified for different intentions. For example, LinkedIn, a platform where individuals can promote their careers and businesses and other employer institutions can recruit and market their commodities, was launched in the vanguard of the social media era in 2004. In addition, journalists and politicians are using social media platforms actively for career promotion [17]. Here, specific groups are leveraging social media for specialized benefits.

The presence of businesses and brands on social media platforms has also become crucial, through improved visibility [21]. Online branding has reached a higher potential through network logic; while media audiences have disintegrated, businesses are able to reach smaller and more specific niches in order to promote their commodities more effectively [32], while consumerism has become an essential 
frame through which people are estimating their actions [3, 41-42]. It has been argued that instead of traditional interestbased collectives, people are rather attached to individual networks [57] and individual expression is displacing collective action frames [1]. In this sense, personal lifestyles, values and views are pronounced in terms of-for example-admiration of different opinion leaders and brands.

This change of consumer culture towards more individual consumerism can also be seen in viral marketing on social media, where products and services are marketed via popular users such as celebrities [20, 22]. In this sense, phenomena such as viral marketing pinpoint the transformation in relationships between brands, consumers and social networks; brands are effectively utilizing the networks formed by consumers to gain economic benefits, while consumers are actualizing themselves by attaching to these networks filled with cultural meanings and symbols.

Like businesses, different social and political organizations are also widely using social media [42, 44]. Social media platforms offer effective tools for organizations, like NGOs, recreation and hobby organizations, and for example sports clubs, to coordinate their activities and communicate with their members and other stakeholders. Also, political parties, organizations and movements have embraced these means of social interactions in their activities. Politicians and party offices have established profiles on social media to affect voters and encourage them to participate in political events. At the same time, new social movements are formed apart from traditional and institutional political collectives online [1]. In this respect, politics and civic engagement have truly integrated into these social spaces.

While these wide social changes in social media spaces have occurred, use purposes connected to these changes ought to be increasing on a population level as access becomes more widespread. By monitoring these changes in different use purposes of social media, we are able to assess how different changes are applied by users of social media. Notably, former theory and research literature provide us with a tool to understand the varying Internet use patterns and social media preferences in different population segments. Earlier literature shows that new beneficial Internet use purposes are first adopted by forerunners, who are likely to be wealthier, educated and young [30, 52]. Notably, this trend towards a more diverse set of use patterns online may still be highlighted by socio-demographic differences.

\section{Social media divides in Finland}

Differences in technology use among various population groups within a society have been described through the term "digital divides". As such, the term illustrates how technology and Internet use, use potential, motivations and necessary skills for effective use are unevenly distributed depending on various socio-demographic characteristics (see $[8,34,52])$. Indeed, highly educated and wealthier population groups tend to have better access to new innovations, more experience with technology use and a greater ability to take advantage of new platforms while also being more capable in improving their own consumption, participation and leisure activities through the Internet (e.g. [7, 43, 50, 52]).

Changes and inequalities in ICT use patterns have been well documented in Finland. Following the vigorous economic growth during the late 1990s, a rapid increase in the supply of the new digital services came about. In 2001, for example, the proportion of individuals aged 15 and over who had used the Internet at least once during the past 3 months was approximately 50 per cent in Finland. By 2016, the same share of Finns was 88 per cent. Furthermore, differences between age groups have diminished, though younger people continue to be the most active Internet users [36].

The formation process of consumption and technology use differences between population groups should be noted. Originally introduced by Rogers [41], differences between population groups are great when a new product is introduced in the market. After these products have become established, the differences between population groups begin to even out as wide-scale adoption emerges. In other words, the connection between technology use and basic socio-demographic characteristics diminishes gradually. In the literature, this has been described as the profilization and standardization of spending and use habits and the diffusion process of the proliferation of products (e.g. [9, 26, 39, 52].

As such, access is a crucial source of inequality, which creates a separating disparity (e.g. [7]), though socio-demographic and socio-economic factors can also influence user motivation and online navigation skill level, and thus, the potential benefits of having access can be unequal. During the new media era, inequality in access to information and the tools involved with accessing it has decreased among population groups $[49,55]$. Here, in the case of social media use, differences in usage patterns can mean differences in access to information and valuable interaction among users even when everyone has access to the platforms in question.

In addition to inequalities in access to social media, digital divides may appear also in different skills connected to social media use, different use purposes and different kinds of benefits gained from the use. For instance, there is significant inequality in the population groups represented in the public discourse happening through social media [43]. Notably, the effective use of social media in professional life can bring about valuable advantages. These disparities following inequalities in access, such as skills and benefits gained from the use, have been referred to as second-level and third-level digital divides [15, 48]. As digitalization has 
continued in Western countries, social media use access differences have arguably decreased (see $[10,14,38]$ ), which does not mean that the benefits from the use are distributed evenly [48].

Finland is considered, as in the case of many other Western European countries, a "mature information society", since mobile phones, computers and the Internet have been widely used and accessed for nearly two decades [11]. Two phenomena characterize this societal status; first, the growth of the proportion of younger age group users has slowed significantly in Finland. Second, as the growth rate has slowed down among younger citizens, the proportion of those who use ICT is still growing among older population segments [25]. What is important to notice here is that clear educational and other socio-demographic differences still associate with different Internet use purposes [33, 40]. In this sense, we are interested in how social media use in general and in certain use purposes has distributed within Finnish society and how these differences have changed between the years 2008 and 2016. With this viewpoint, we are able to also assess how different benefits gained from social media use are allocated in the Finnish context.

\section{Research design}

Our goal is to provide a new frame for understanding everchanging digital divides. The focus of empirical analysis is to study the differences in the popularity of social media use and in use purposes over time between different population groups. We summarize the following two research questions:

1. How did registered social media use change in Finland during the years 2008-2016?

2. How did the purposes of social media use change between the years 2012 and 2016 ?

Our first hypothesis (H1) is that the overall social media use has become more popular and use purposes have become more diversified between the years 2008 and 2016. Here, we assume that social media use has become more popular across population groups. We also assume that the adaptation of social media use has resulted in more versatile use purposes (e.g. [24]). During this process, conventional networking activities are likely partly replaced by other daily activities such as following and promoting working-life issues, and current cultural and political affairs. Preceding literature suggests that use purposes have generally changed towards more bringing about more commercialized and personalized goals [51, 57], in addition to the politicization of social media [1]. Here, we expect to find significant changes of overall use at the population level from 2008 to 2016. In addition, we expect to find that the differences in use purposes have increased among population groups during the time period 2012-2016.

Our second hypothesis $(\mathrm{H} 2)$ is that the overall use and use purposes of social media continue to vary significantly between socio-demographic groups. In preceding research, it has been noted that younger age groups use social media for social interaction, leisure and, for example, instrumental self-promoting purposes more often than older age groups $[16,37,46]$. Similarly, we expect that women tend to use social media more often for social, relational and leisurerelated purposes, while men are generally more oriented towards work-related purposes [5]. We also assume that the highly educated use social media for workplace task effectiveness, which has been shown in past research [50] through career promotion [17] and participation in political discourse $[19,43]$. On the other hand, we expect that less educated users will tend to use social media more for leisure purposes (see [50]). Finally, people living outside of big cities are less active social media users compared to those living in urban areas (e.g. [38]). Therefore, we assume that the use of social network applications is generally less common in rural areas when compared to urban areas.

While the existing disparities between socio-demographic segments are often acknowledged in ICT literature, it is stressed that the existing disparities in access tend to diminish over time [52]. This is especially true for rapidly penetrating consumer technologies (e.g. [29, 35]). Such notions lead us to expect that the differences in the degree of social media use among population groups have diminished over the past decade. Thus, an additional assumption to our second hypothesis is that while overall social media use has become more common across population groups, the use frequencies associating with basic socio-demographic factors have leveled off during the period 2008-2016. Naturally, we still expect to find that younger, highly educated individuals and city dwellers continue to be more likely to be social media users than others in each year (e.g. [38, 43, 50]). Therefore, with regard to $\mathrm{H} 2$, we are not assuming to find notable differences in the socio-demographic disparities in social media use purposes when comparing 2012 and 2016.

\section{Data}

Our analysis is based on the "Use of information and communications technology by individuals" data for the years 2008, 2010, 2012, 2014 and 2016. The raw data were provided by Statistics Finland, while also being the source for official Finnish statistics (see [36]). This cross-sectional survey assesses the commonality of technology and online platform use, frequency of use, diversity, use purposes, use locations and online shopping. Yearly participant quantity has differed between 2255 and 2730 , out of the 4300 and 4850 
Table 1 Descriptive statistics of datasets

\begin{tabular}{llll}
\hline Year & $N$ & Sample & Response mode \\
\hline 2008 & 2883 & 4300 & Phone \\
2010 & 2761 & 4300 & Phone \\
2012 & 2704 & 4300 & Phone \\
2014 & 2312 & 4850 & Phone \\
2016 & 2255 & 4850 & Phone + Internet \\
\hline
\end{tabular}

individuals randomly selected from the population register. While official Finnish statistics are published online (see [36]), detailed analysis of these data by population group has not yet been carried out and findings based on controlling for various background variables thus remain undone before this study. The descriptions of datasets are given in Table 1 .

The surveys used in this article had reached approximately 12,000 Finnish participants from 2008 to 2016, providing a prolific representative starting point. From 2008 to 2014, the response rate was relatively high when both contacting and interviewing were carried out by telephone. However, in 2016, after moving into to the mixedmode survey, the response rate dropped to 46 per cent. The mixed-mode survey denotes that multiple data collection approaches were used in one collection (e.g. [6]). In this survey, respondents were contacted by mail and were offered the opportunity to respond to the questionnaire via a webbased application or telephone interview.

We compensated for the variation in sample sizes by taking advantage of Statistics Finland's weight factor variables, which are also included with post-stratification balancing. Since the data offer the official figures for Finnish ICT usage, various demographic information ranging from education and place of residence to family composition has been used to correct for the population and sample biases (for details, see [36]).

\section{Measures and analytic techniques}

In addition to the direct distribution information provided by Official Statistics of Finland, we also carry out an indepth analysis of the temporal variance and the effects of background variables. First, we examine population trends in social media use between the years 2008 and 2016. In the original question, participants were asked about social media activity in terms of whether he or she had registered or made a profile on a social networking site such as, for example, Facebook, Twitter or LinkedIn. ${ }^{1}$ Respondents were

\footnotetext{
1 The original question is: "Next we are going to ask about the use of the Internet's social networking services, such as Facebook, Twitter, or LinkedIn. Have you registered on the Internet's social network-
}

able to choose whether they had registered a profile (1) in one networking site, (2) in several networking sites or (3) do not have registered profile on any networking sites. In our analyses, we use a binary variable where a value of 0 represents those participants who are not registered on social media platforms and value 1 represent those who are registered users.

After the examination of social media use across population groups, we will examine purposes of social media usage, which were asked in 2012 and in 2016 questionnaires. Questions considering different use purposes are asked only in the years 2012 and 2016, which limits our analyses only to those years. We measured a total of 10 use purposes, which estimate how social media is used to social activities, social and leisure organizations, work- and career-related issues, commercialized purposes and political purposes. Participants were asked whether they use social media for "interaction with friends", "interaction with family", "hobbies", "social organizations", "work-, career- or business-related purposes", "following corporations' brands, products or services", "participating to fan networks or fan pages", "participating to phenomena, events or demonstrations formed online", "societal or political issues (such as following politics or participating political action)", and "something else". Here, a value of 1 represents users of certain purpose and value 0 non-users. These analyses were conducted by focusing solely on social media users that were defined in the first section of analysis. Different use purposes are presented in Table 2 with descriptive statistics.

In terms of independent variables, we take into account respondents' gender, age, education and residential area. Age was categorized into six age groups, 16-24, 25-34, $35-44,45-54,55-64$ and $65-74$. This was done to gather accurate information across different age groups despite the high level of errors when the analysis is focused on social media users alone in terms of the second research question. Respondents' education was categorized on the basis of the ISCED classification into four groups according to whether he or she had completed basic, upper-secondary, bachelor or at least master's-level education. Information on respondents' place of residence was categorized according to current domicile either as metropolitan, other city area (over 80,000 inhabitants), town or countryside. More detailed statistics of independent variables are presented in Table 2.

Our analysis techniques were based on proportion comparisons across different populations. In addition, we tested the temporal variance in both sections of analysis with logit models by using women, 16-24-year-olds, primary educated

\footnotetext{
Footnote 1 (continued)

ing sites?" In addition, there was a clarification "Do not include direct
} messaging services such as WhatsApp". 
Table 2 Descriptive statistics for applied variables, unweighted means and standard deviations

\begin{tabular}{|c|c|c|c|c|c|}
\hline Variable & $N$ & Mean & SD & Min & $\operatorname{Max}$ \\
\hline \multicolumn{6}{|l|}{ Dependent } \\
\hline \multicolumn{6}{|l|}{ Use of social media } \\
\hline Have registered on a social media platform & 11,181 & 0.49 & 0.50 & 0 & 1 \\
\hline \multicolumn{6}{|l|}{ Purpose of use } \\
\hline Friends & 2490 & 0.90 & 0.30 & 0 & 1 \\
\hline Family & 2490 & 0.62 & 0.49 & 0 & 1 \\
\hline Hobbies & 2626 & 0.15 & 0.35 & 0 & 1 \\
\hline Social organizations & 2626 & 0.35 & 0.48 & 0 & 1 \\
\hline Work, career or business & 2490 & 0.32 & 0.47 & 0 & 1 \\
\hline Following brands, products or services & 2490 & 0.35 & 0.48 & 0 & 1 \\
\hline Following fan networks or fan pages & 2490 & 0.23 & 0.42 & 0 & 1 \\
\hline Online phenomena & 2490 & 0.24 & 0.43 & 0 & 1 \\
\hline Politics or societal issues & 2490 & 0.15 & 0.36 & 0 & 1 \\
\hline Other & 2036 & 0.07 & 0.26 & 0 & 1 \\
\hline \multicolumn{6}{|l|}{ Independent } \\
\hline Gender & 11,181 & 0.50 & 0.50 & 0 & 1 \\
\hline Mean age & 11,181 & 44.40 & 16.06 & 16 & 74 \\
\hline Primary education & 11,181 & 0.21 & 0.41 & 0 & 1 \\
\hline Secondary education & 11,181 & 0.42 & 0.49 & 0 & 1 \\
\hline Tertiary education & 11,181 & 0.25 & 0.43 & 0 & 1 \\
\hline Master's education & 11,181 & 0.12 & 0.32 & 0 & 1 \\
\hline Metropolitan area & 11,181 & 0.20 & 0.40 & 0 & 1 \\
\hline City & 11,181 & 0.20 & 0.40 & 0 & 1 \\
\hline Town & 11,181 & 0.29 & 0.45 & 0 & 1 \\
\hline Rural & 11,181 & 0.31 & 0.46 & 0 & 1 \\
\hline
\end{tabular}

and those living in metropolitan area as reference categories. Due to the rescaling problem of nested nonlinear models, we conducted logit models by using the KHB method [23]. With regard to general use, we are interested in determining whether there has been an increase or decline in differences between the population groups. Accordingly, we first analysed the direct effect of each independent variable, and secondly, we assessed the temporal variance by estimating the effects of year on each independent variable step by step while controlling for the effect of other independent variables. When moving into use purposes, we tested the effect of background variables on the temporal variance by changing the year as the main independent variable. Here, our interest is to determine whether the temporal variance is visible among certain population groups.

\section{Registered social media use 2008-2016}

We first estimated the proportion of registered social media users according to different population groups during 2008-2016. Figure 1 shows unadjusted estimates for different population groups between the years 2008 and 2016. As seen in the figure, the use of social media has increased in all population groups since 2008. Age has the most notable effect here. Over 90 per cent of those under the age of 35 were registered on some social networking sites in 2016, though during the $2010 \mathrm{~s}$ growth slowed within younger age groups, which is unsurprising given that young people tend to be the early adopters of social media by a significant margin $[5,27]$ and that growth in a boom of early adoption naturally subsides more quickly compared to other population groups [41]. During the present century, growth has been greatest among the age group 35-44. However, it is also noteworthy that the use of social media accelerated among the age groups 45-54 and 55-64 after 2010. There are also statistically significant differences between genders, different education groups and between people living in different districts in every unadjusted model. In order to interpret differences between population groups and temporal changes of social media use, more sophisticated methods are required.

The statistical tests for year effects are shown in Table 3. Notably, it seems that the increase of social media use has been universal in all demographic factors with the exception of the increase between age groups. As seen in the table, the differences between the oldest and the youngest age groups increased after adjusting the temporal variance. This notion is also visible when taking a closer 

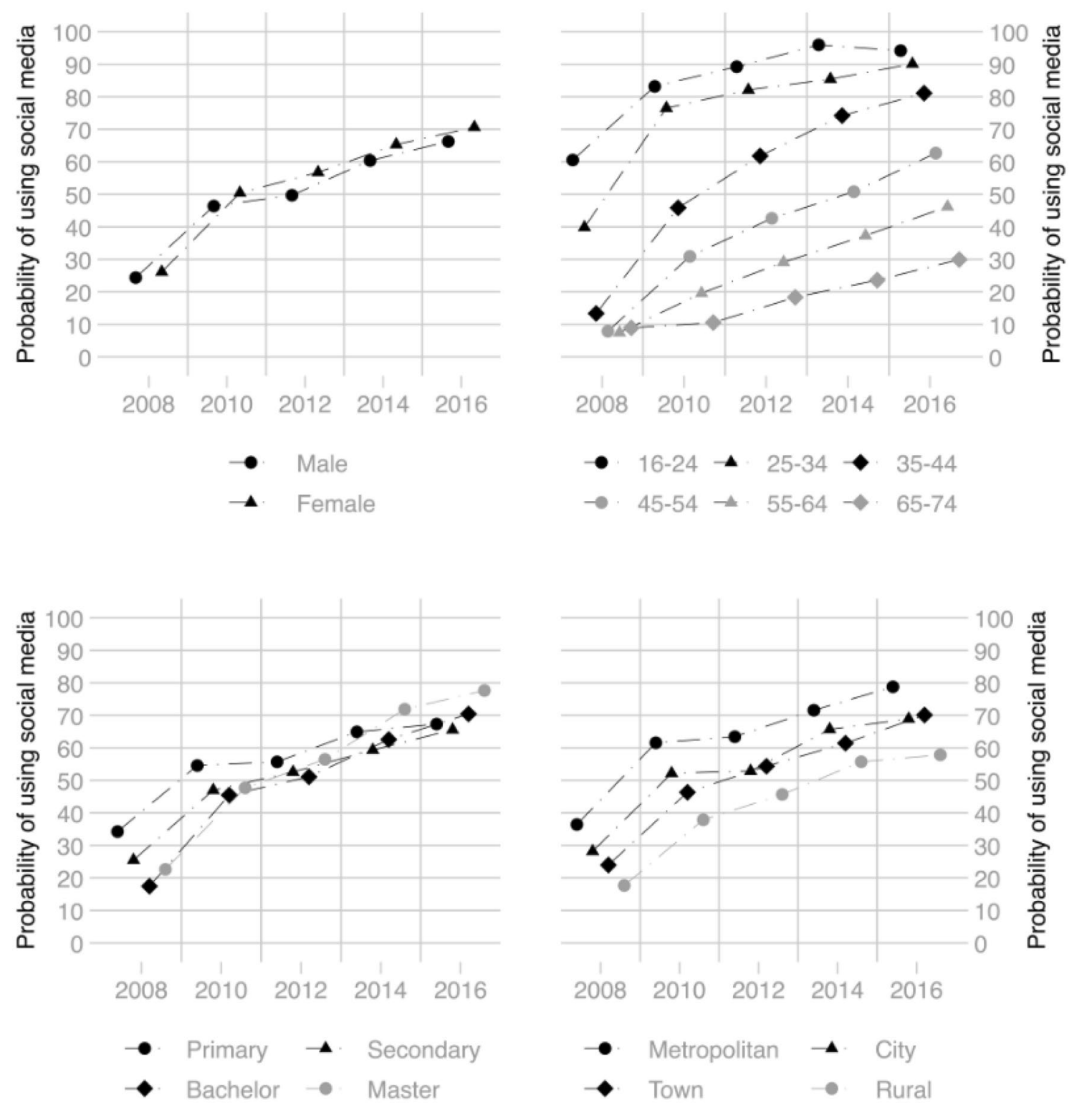

Fig. 1 The proportion of social media users by gender, age, education and residential area, unadjusted estimations 2008-2016

look to the descriptive analysis in Fig. 1, which shows that the difference between the oldest and the youngest groups has even increased between 2008 and 2016.

Interestingly, differences between genders, education groups or different regions were not significantly mediated or confounded by year effect. Growth has been similar among respondents from both genders, all education groups and people from all regions, and there is no statistically significant indirect year effect between these population categories. However, these models confirmed previously presented descriptive results by providing adjusted effects for each independent variable, which reveal the long-lasting divides between population groups.
First, the use of social media was not equally distributed for both men and women, as women were slightly (5 percentage points) more active users after controlling for other independent variables. As expected, education also has a significant effect. During the observation period, there was, on average, a 10 percentage-point difference between the highest and the lowest education groups, while the most educated Finns were the most active social media users. Also, regional differences are quite strong in Finnish society, as those living in metropolitan areas were approximately 10 percentage points more likely to be social media users. The lowest level of social media use is in rural regions. This effect remained significant throughout the years 2008-2016. 
Table 3 Social media usage by background variables with the decomposition of year effect

\begin{tabular}{|c|c|c|c|c|c|c|c|}
\hline \multirow{2}{*}{ Gender } & \multicolumn{2}{|c|}{ Adjusted direct effect } & \multicolumn{3}{|c|}{ Total effect with year } & \multicolumn{2}{|c|}{ Indirect year effect } \\
\hline & & & & & & & \\
\hline Men & Ref. & & & & & & \\
\hline Women & $0.29 * * *$ & $(0.05)$ & $0.29 * * *$ & $(0.05)$ & {$[0.05]$} & 0.00 & $(0.02)$ \\
\hline \multicolumn{8}{|l|}{ Age } \\
\hline $16-24$ & Ref. & & & & & & \\
\hline $25-34$ & $-0.93 * * *$ & $(0.10)$ & $-0.97 * * *$ & $(0.10)$ & {$[0.12]$} & 0.04 & $(0.08)$ \\
\hline $35-44$ & $-2.07 * * *$ & $(0.10)$ & $-2.10 * * *$ & $(0.10)$ & {$[0.32]$} & 0.03 & $(0.08)$ \\
\hline $45-54$ & $-2.81 * * *$ & $(0.10)$ & $-2.88 * * *$ & $(0.10)$ & {$[0.48]$} & 0.06 & $(0.08)$ \\
\hline $55-64$ & $-3.29 * * *$ & $(0.10)$ & $-3.43 * * *$ & $(0.10)$ & {$[0.58]$} & 0.15 & $(0.08)$ \\
\hline $65-74$ & $-3.72 * * *$ & $(0.11)$ & $-4.11 * * *$ & $(0.12)$ & [0.69] & $0.39 * * *$ & $(0.08)$ \\
\hline \multicolumn{8}{|l|}{ Education } \\
\hline Primary & Ref. & & & & & & \\
\hline Secondary & 0.04 & $(0.07)$ & 0.01 & $(0.07)$ & {$[0.00]$} & 0.02 & $(0.06)$ \\
\hline Tertiary & $0.39 * * *$ & $(0.08)$ & $0.39 * * *$ & $(0.08)$ & {$[0.07]$} & -0.00 & $(0.06)$ \\
\hline Master's & $0.65 * * *$ & $(0.09)$ & $0.61 * * *$ & $(0.09)$ & {$[0.10]$} & 0.04 & $(0.06)$ \\
\hline \multicolumn{8}{|c|}{ Residential area } \\
\hline Metropolitan & Ref. & & & & & & \\
\hline City & $-0.46 * * *$ & $(0.08)$ & $-0.55^{* * *}$ & $(0.08)$ & [0.09] & 0.08 & $(0.05)$ \\
\hline Town & $-0.53 * * *$ & $(0.07)$ & $-0.50 * * *$ & $(0.07)$ & {$[0.08]$} & -0.03 & $(0.05)$ \\
\hline Rural & $-0.80 * * *$ & $(0.07)$ & $-0.73 * * *$ & $(0.07)$ & {$[0.12]$} & -0.07 & $(0.05)$ \\
\hline
\end{tabular}

Robust standard errors in parentheses. Average partial effects for total effects in brackets. Including four models: each independent variable modelled separately with year effect by holding other independent variables as constant

$* * * p<0.001, * * p<0.01, * p<0.05$
These results contradict our hypothesis, as we expected that differences between population groups would have declined during the survey period.

\section{Social media use purposes in 2012 and 2016}

Next, we assessed whether the social media use purposes have changed between 2012 and 2016. As seen in Fig. 2, there was significant temporal variation in most of the purpose categories. Striking here is that the social impact of social media seems to have decreased, as the utilization of social media for maintaining hobbies, forming friendships or civic participation has declined significantly. Interestingly, the use of social media for work and following various brands, along with political participation, have increased significantly.

In Figs. 3, 4, 5 and 6, we present proportions of different social media use purposes according to different population groups. This analysis confirmed our hypothesis that women use social media significantly more often for maintaining family ties and for social interaction with friends. In contrast, it was also revealed that men used social media for hobby organizations in 2012 more often compared to women, but the difference has diminished since then. Men were also using social media slightly more for work- and career-related purposes.

As expected, the significance of age is higher in activities having to do with work and politics as well as those activities linked to entertainment and leisure. Those in the prime of their careers are more likely than others to use social media for work and career purposes. The entertainment factors were smallest among the oldest participants, while younger participants were more likely to follow brands and belong to fan networks or follow fan pages. Also, there was a minor difference between the youngest and the oldest participants when considering social media use for hobby and recreation organizations.

The effect of education was the greatest in terms of work and political activity, as those with a postgraduate degree were most active. Interestingly, respondents with only primary education used social media for fan networks or fan pages the most actively. Area of residence was apparent in use for work and career likelihood as well, while people living in metropolitan areas used social media more actively than people living in rural areas for these purposes.

According to the descriptive analysis, changes in use purposes seem to be fairly general as there were similar differences between demographic patterns across years. 


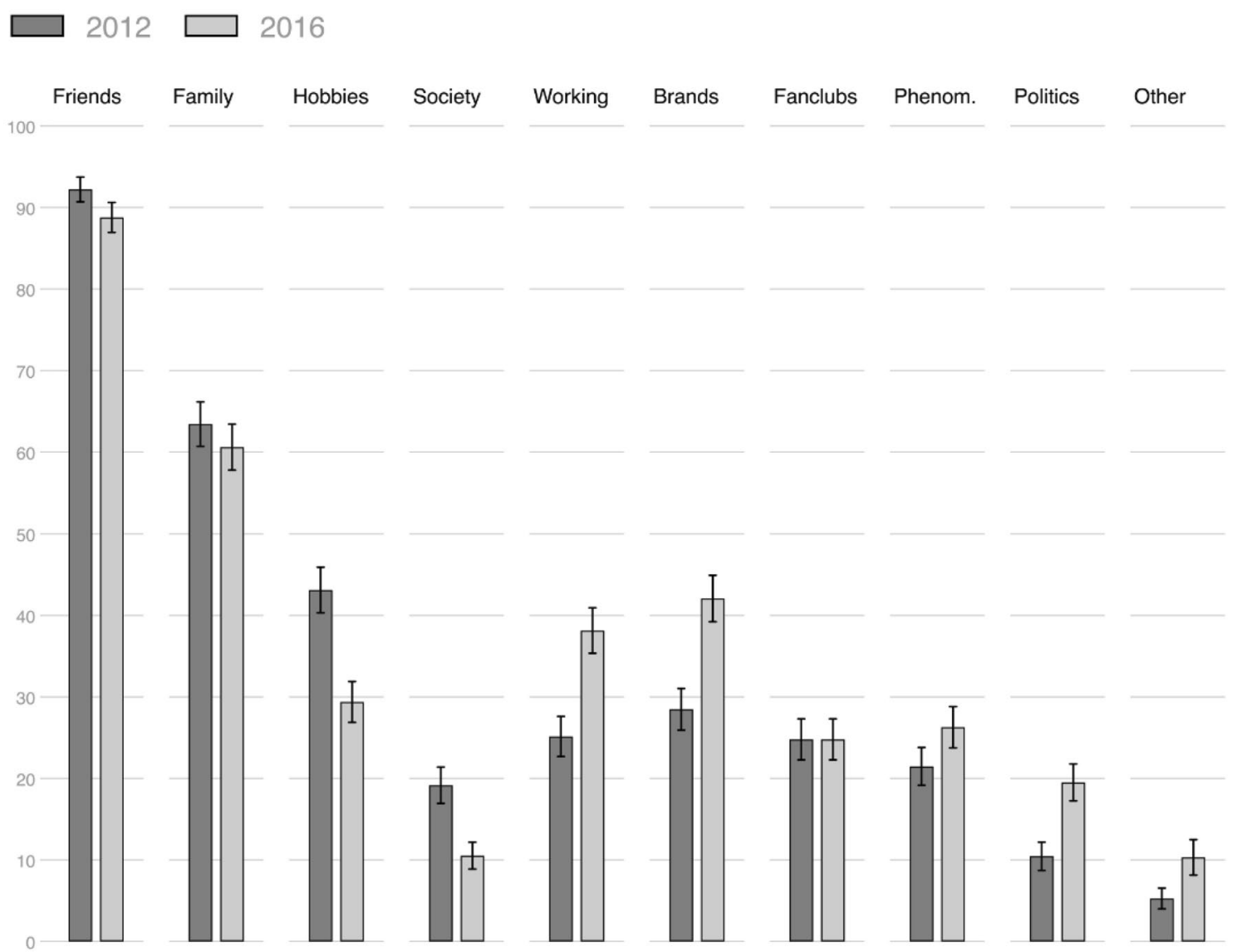

Fig. 2 Proportions of different social media usage purposes among registered users in 2012 and 2016

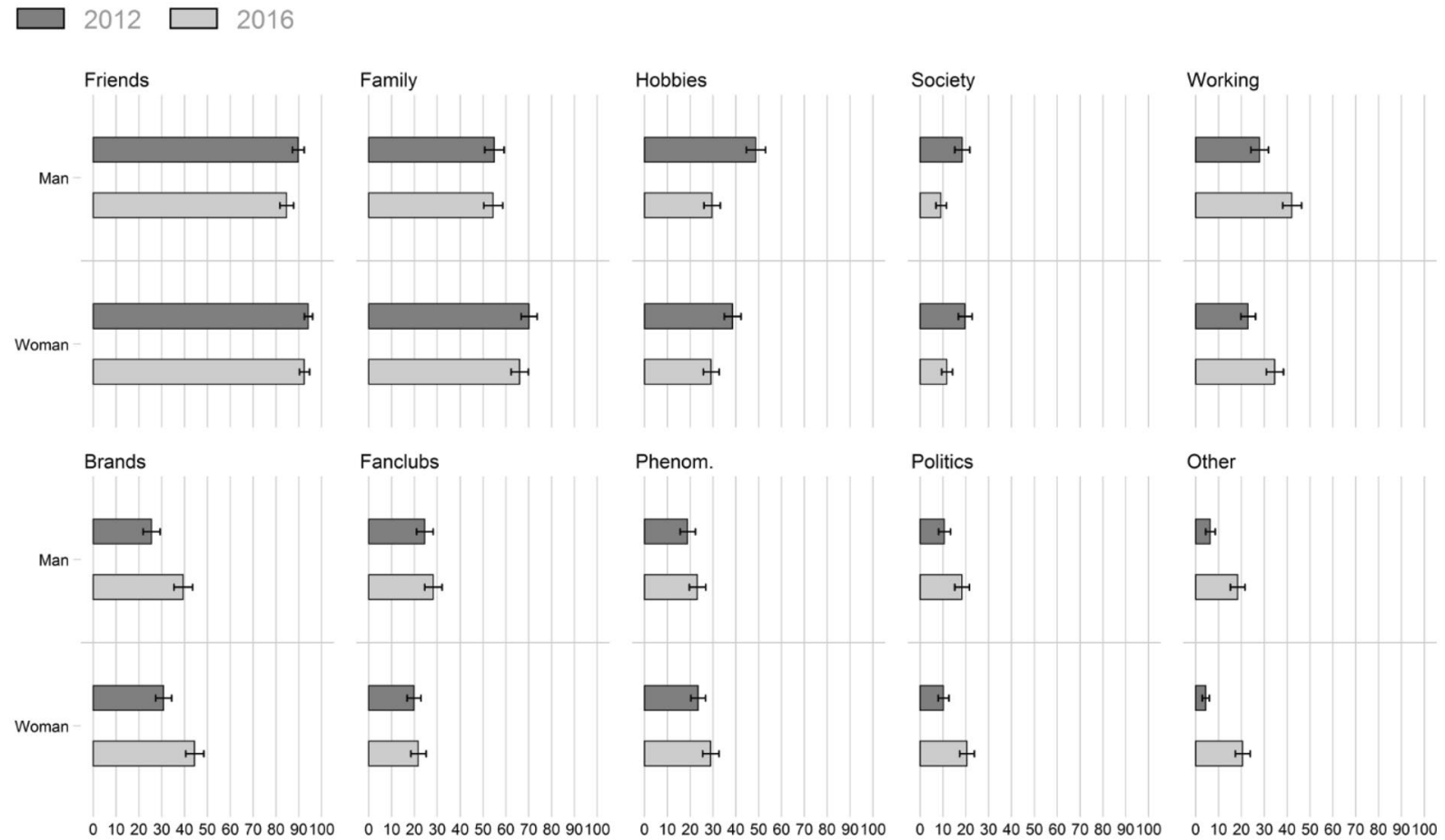

Fig. 3 Proportions of different social media usage purposes among registered users in 2012 and 2016 by genders 
$2012 \square 2016$

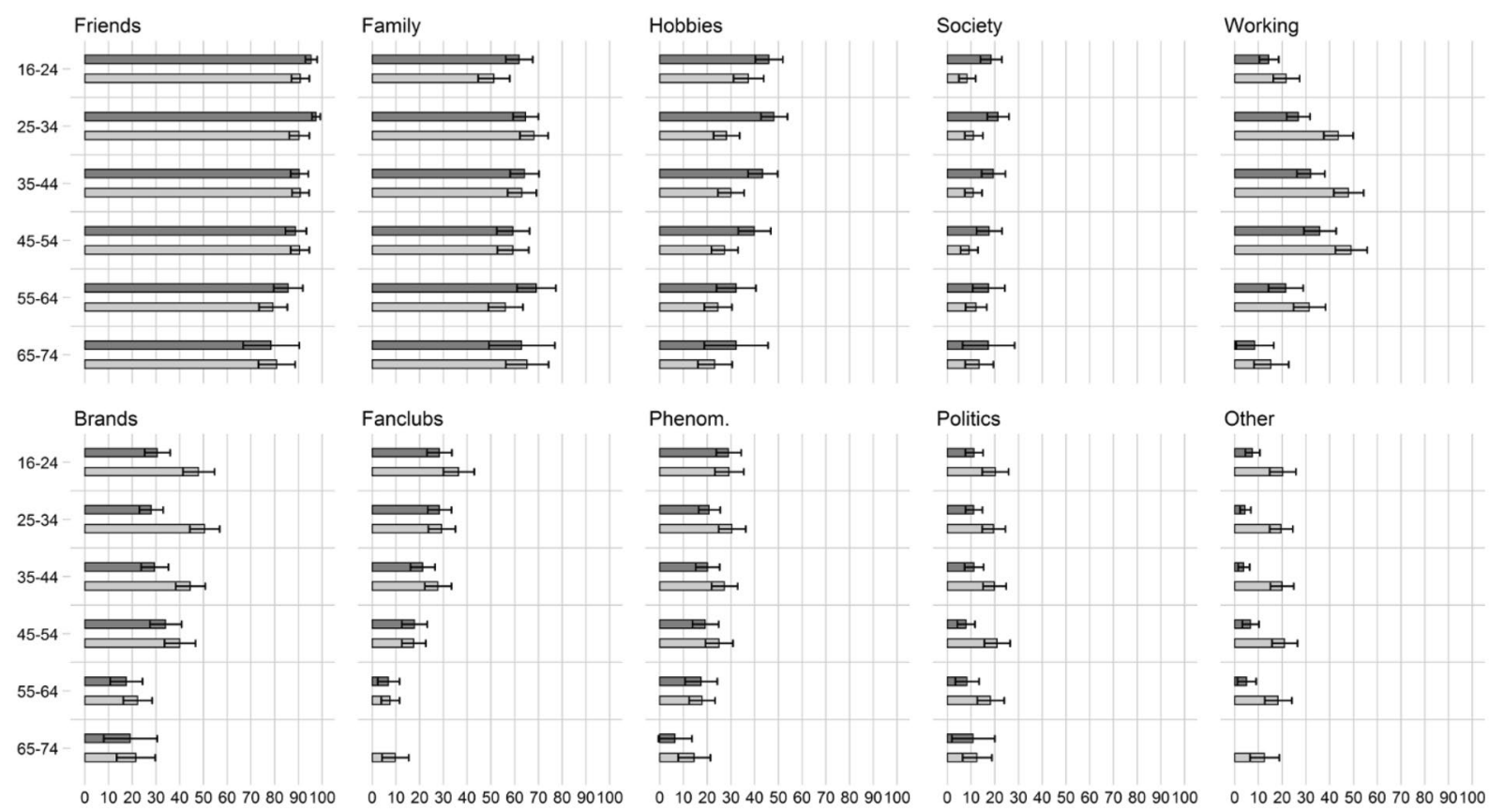

Fig. 4 Proportions of different social media usage purposes among registered users in 2012 and 2016 by age groups

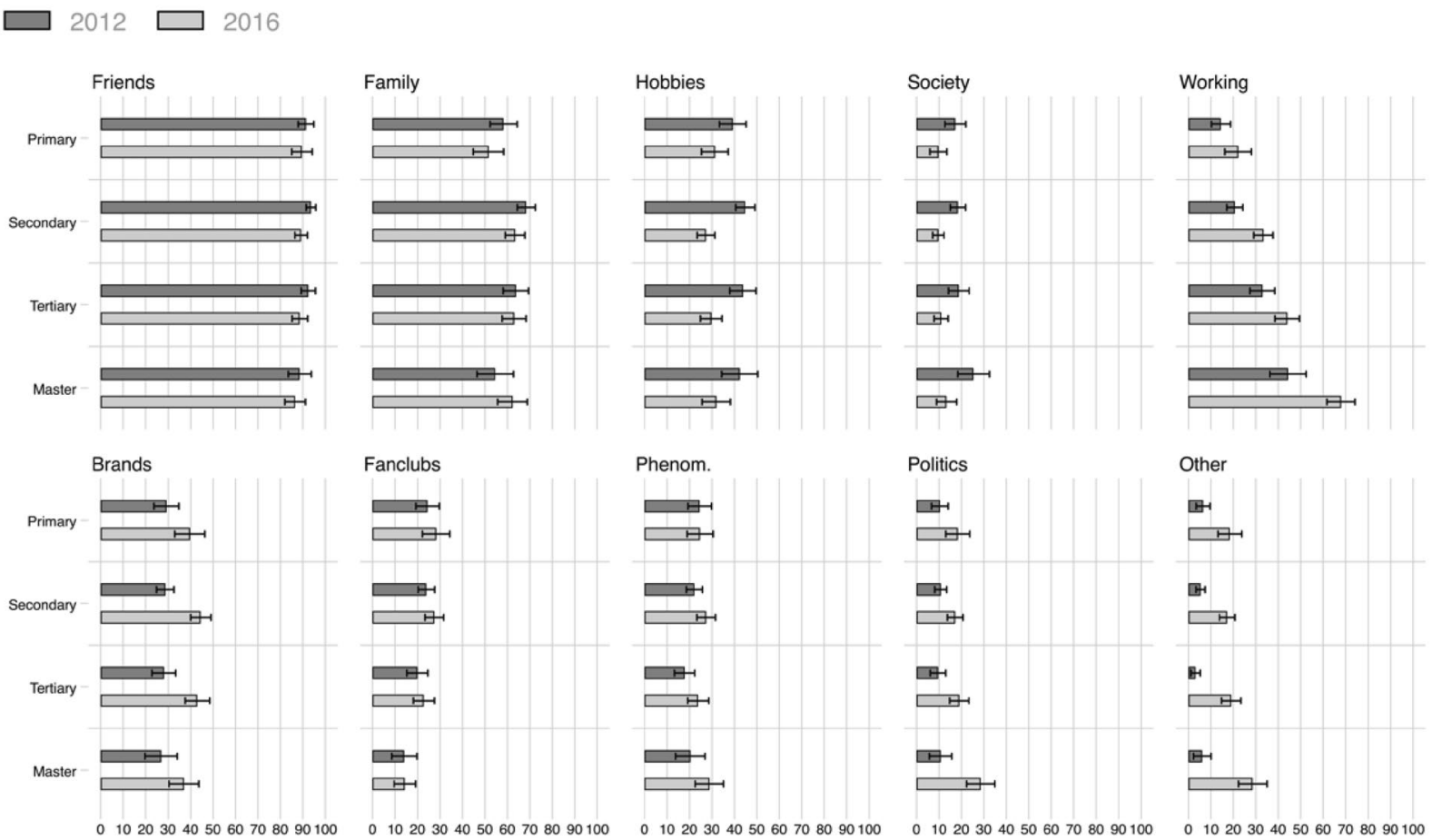

Fig. 5 Proportions of different social media usage purposes among registered users in 2012 and 2016 by education groups

Next, we test this assumption by decomposing year effect for each dependent variable with independent variables. Here, the main interest is in the adjusted effects of year and also the potential indirect effects of some background variables. If the adjusted effect of year remains similar and statistically significant after decomposition, we may put 
$2012 \square 2016$
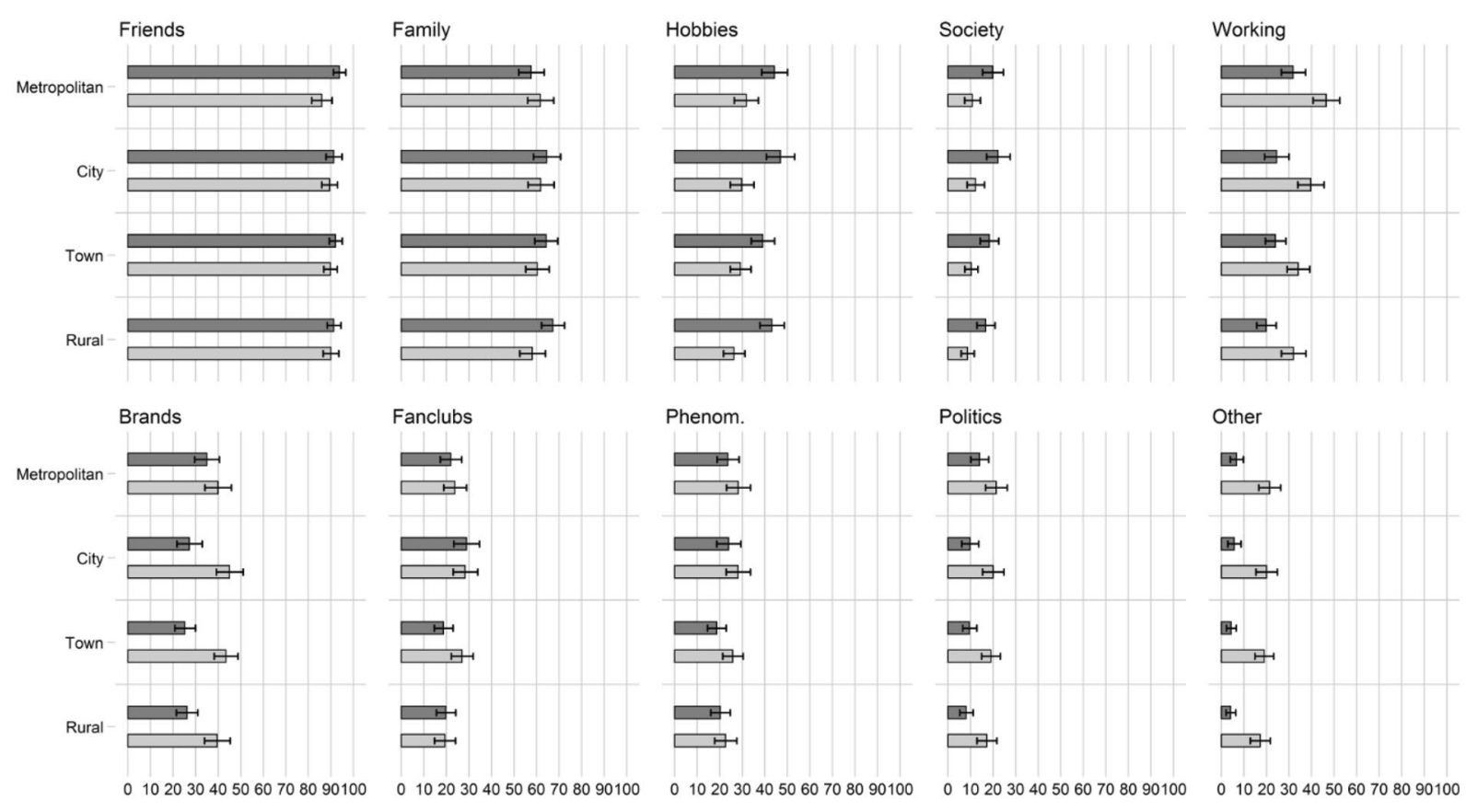

Fig. 6 Proportions of different social media usage purposes among registered users in 2012 and 2016 by regions

Table 4 Decomposition of year effects (2016 vs 2012) on social media usage purposes by demographic factors

\begin{tabular}{|c|c|c|c|c|c|c|c|c|c|c|}
\hline \multirow{3}{*}{$\begin{array}{l}\text { Adjusted effect of year } \\
\text { Indirect effect of year vic }\end{array}$} & \multicolumn{2}{|l|}{ Friends } & \multicolumn{2}{|l|}{ Family } & \multicolumn{2}{|l|}{ Hobbies } & \multicolumn{2}{|c|}{ Social organization } & \multicolumn{2}{|l|}{ Working } \\
\hline & $-0.082^{*}$ & $(0.037)$ & -0.026 & $(0.022)$ & $-0.145^{* * *}$ & $(0.021)$ & $-0.179 * * *$ & $(0.029)$ & $0.160 * * *$ & $(0.024)$ \\
\hline & & & & & & & & & & \\
\hline Gender & -0.006 & $(0.004)$ & -0.004 & $(0.003)$ & 0.002 & $(0.001)$ & 0.003 & $(0.002)$ & 0.003 & $(0.002)$ \\
\hline Age & $-0.013 * *$ & $(0.005)$ & 0.000 & $(0.001)$ & $-0.009 * *$ & $(0.003)$ & -0.002 & $(0.002)$ & -0.002 & $(0.002)$ \\
\hline Education & 0.000 & $(0.001)$ & -0.002 & $(0.002)$ & -0.001 & $(0.001)$ & -0.003 & $(0.006)$ & -0.003 & $(0.006)$ \\
\hline \multirow[t]{2}{*}{ Residence } & -0.001 & $(0.001)$ & 0.000 & $(0.001)$ & 0.000 & $(0.001)$ & 0.001 & $(0.002)$ & 0.001 & $(0.002)$ \\
\hline & \multicolumn{2}{|l|}{ Brands } & \multicolumn{2}{|c|}{ Fan networks } & \multicolumn{2}{|l|}{ Phenomena } & \multicolumn{2}{|l|}{ Politics } & \multicolumn{2}{|l|}{ Other } \\
\hline Adjusted effect of year & $0.164 * * *$ & $(0.023)$ & $0.054 *$ & $(0.025)$ & $0.072 * *$ & $(0.025)$ & $0.185^{* * *}$ & $(0.030)$ & $0.178 * * *$ & $(0.045)$ \\
\hline \multicolumn{11}{|l|}{ Indirect effect of year via } \\
\hline Gender & -0.002 & $(0.001)$ & 0.002 & $(0.002)$ & -0.002 & $(0.001)$ & -0.001 & $(0.001)$ & 0.003 & $(0.003)$ \\
\hline Age & $-0.009 * *$ & $(0.003)$ & $-0.015^{* *}$ & $(0.005)$ & $-0.007 * *$ & $(0.003)$ & -0.003 & $(0.002)$ & -0.002 & $(0.003)$ \\
\hline Education & 0.000 & $(0.001)$ & -0.002 & $(0.002)$ & 0.000 & $(0.001)$ & 0.001 & $(0.002)$ & -0.000 & $(0.003)$ \\
\hline Residence & -0.000 & $(0.001)$ & 0.003 & $(0.002)$ & 0.000 & $(0.001)$ & 0.001 & $(0.002)$ & 0.002 & $(0.002)$ \\
\hline
\end{tabular}

Conditional logit coefficients with robust standard errors in parentheses

$* * * p<0.001, * * p<0.01, * p<0.05$

forth a conclusion of a general trend. In contrast, if indirect effects emerge and the adjusted effect of year alters significantly, any increase or decline is dependent on the changes of use purposes in certain demographic groups. For the sake of clarity, we focused solely on the significant effects that emerged from the descriptive analysis (Figs. 3,
$4,5,6)$. Accordingly, we test whether the year effect is explained by difference use among women, master's-level educated and those living in rural area, while other categories are held as covariates. The age effect was tested with a continuous variable. 
The results of the decomposition are presented in Table 4 . The table row for adjusted year effect shows how much the popularity of certain use purpose has changed between 2012 and 2016 when the background variables are controlled for. The indirect effects provide more information about the effects of background variables, showing how much these variables contributed to the temporal variance in use purposes between 2012 and 2016 .

Temporal variance remained significant even after controlling for background variables, except for social interaction with family. However, age had a statistically significant effect on social interaction with friends, and participating in societal online phenomena, hobby and recreation organizations and following brands. We analyzed this more deeply by comparing effects of different age groups. The detailed analysis revealed that using social media to social interaction with friends has declined solely among the two youngest age groups. Utilizing social media to hobbies has decreased significantly only among 25-54-year-olds, while participating in societal phenomena formed online increased among 25-54-year-olds. The likelihood of following brands has increased only among the three youngest age groups.

\section{Discussion}

The role of the Internet continues to be a central one in the lives of people in societies where ICT trends are set, like in the case of Finland. Interaction, expression and consumption continue to be mediated by various forms of social media where validation, entertainment and information abound in ever-increasing quantities. Given the popularity of social media and past links to inequality in access, it becomes relevant to assess online consumption patterns in the light of various participant socio-demographic and economic characteristics in order to shed light on any existing disparities in terms of both primary and secondary digital divides. This study is the first to have leveraged the national statistical data in question through statistical tests and standardizing background variables in order to make novel comparisons between population group social media use.

In our study, age, gender, education level and area of residence were all included in order to assess how social media use might differ among various population groups towards deepening our understanding of social media use dynamics across a high ICT use population. These variables were assessed through survey data administered to Finns between the ages of 15-89. Through the included surveys, each respondent assessed himself or herself towards determining various social media use preferences. The findings of the study were in large part in line with past work while also providing new dimensions of comparison between social media use and key demographic factors.
First, our assumption regarding the degree of social media use among different population groups (H1) was confirmed. The findings are in line with past research in that the likelihood of social media use has increased for all population groups from the year 2008 onwards in Finland and other Western countries, representing a general technological trend (see $[10,14,36,38]$ ) and use purposes have also diversified. As such, the explosion in consumer mobile technology use and potential applications has become a normal part of daily life across socio-demographic groups to the extent that the growth trend continues [28]. In this respect, it is possible that the ubiquity of mobile technologies and the social media platform applications therein have crossed socio-demographic groups in becoming a prioritized norm across population groups beyond what was possible in earlier years when access and mobile applications were less available [49].

Our second hypothesis related to the persisting significance of socio-demographic factors (H2). Our hypothesis was confirmed as age had the most prominent effect on registered social media use. Also, other socio-demographic factors were found to have a clearly smaller impact and these effects did vary significantly over time. These findings are in line with past research on the popularity of social media among younger people (e.g. [14, 24, 38].

However, the growth trends of social media popularity yielded surprising results as well. We were also concerned with the socio-demographic differences in use purposes. We assumed that differences between use purposes had increased when comparing 2012 and 2016. Again, age was the most prominent factor here. Commercialized use habits especially have become more common among younger users. Also, social media use for participating in new societal phenomena was more common among under 25 -year-olds. Accordingly, social media use for work and career promotion was more common for middle-aged people. Furthermore, education continues to play a significant role in different use habits, especially when social media is used for political purposes and work-related activities. In use purposes where societal and economic benefits are clear, the most educated are and have been the most active. These findings illustrate the socio-demographic differences based on a more nuanced and specialized use of social media.

Area of residence or region remained significant throughout the years included in the study. Those living in rural areas were the least likely to use social media, which may come as a surprise given the variety of social tools, entertainment and avenues for expression available through social media that could be viewed as an attractive contrast for those living in less socially diverse areas. However, people living in a metropolitan region are more likely to use social media for work and career purposes compared to people living in 
rural regions. This may have to do with the fact that Finnish labour markets are highly segregated in terms of region.

In terms of gender, women have been slightly more active social media users since 2010, but the distance between genders has diminished since the highest peak in 2012. Female participants favoured relational use purposes, which was in line with past findings [5].

In general, results showed that the growth of social media use slowed during the 2010s while the greatest growth of this decade is among those over the age of 35 . This finding may very well reflect the wearing off of the novelty effect of new platforms and technologies, where adoption rates are high early on and level out after novelty becomes the norm. Notable here, however, is the high growth of use among the middle-aged population. Indeed, this may very well be a case of trickle-down technology adoption, where the use patterns of younger people pave the way for older generations to step into social media use.

In terms of temporal effects, the most striking result is that changes in usage purposes seemed to be fairly general as differences between categories were similar at both observation periods. In this respect, we may put forth a conclusion that there has been a shift in how social media is used, as the social impact of social media seems to have declined while its use is increasingly addressed to consumer culture and more individualized purposes, such as career promotion and political participation. These use purposes have, in the past, been less prominent features of social media platforms whose primary focus has been on encouraging socialization and relational development. Together, our observations highlight the fact that digital divides have emerged through the evolution of social media, based not only on access but also on type and quantity of benefits gained through amplifying advantages of offline differences and social networks. This finding is significant for social media research, as it sheds light on the nuanced inequalities that can emerge as various population groups implement their offline lives in an online social media platform in increasingly specific ways to further personal goals.

Despite providing novel findings for Finnish social media use, the study is limited in that Finland should not be considered representative of Europe as a whole. However, the case of Finland is particularly valuable in terms of technology use trends due to it being a leader in consumer technology usage patterns and early adoption that may be useful in projecting usage patterns in other countries. Secondly, when it comes to temporal analysis, our study utilized solely crosssectional waves of simple random samples. Even though samples were drawn from the national population register, the data are not equivalent to panel samples in which the observations come from the same respondents each year. As is the case in survey research in general, it is important to note that participant opinions about the definitions of social networking sites may have changed during this century. New social networking platforms, such as Instagram and Snapchat, are differing from more traditional platforms such as Facebook, which may cause younger respondents especially, who are using novel social media platforms, to misunderstand the survey questions. In the same way, instant messaging applications, such as WhatsApp, Facebook Messenger and Kik Messenger, can be understood as social media platforms that offer a similar setting for social interaction, albeit for smaller interacting groups. As such, the emergence of novel social media platforms forms a constantly changing environment that requires new qualitative and quantitative research as well evolving theoretical discussions. Despite these limitations, the study provides a comprehensive look at social media use among a national population, which future research can compare to adoption rates and use patterns of similar demographics involved with the next generation of technology trend use.

\section{Conclusion}

Overall, this study represents the first temporal look at past changes of social media use in Finnish society using representative population-level data, which offers important information for researchers focused on social media and online communities as well as for social media marketing professionals and social media companies. The findings of this study concerning the various social media use patterns among different population groups within Finland show that they do indeed overlap to a great degree in terms of what is being done and where. Additionally, findings show how commercialization and politicization of online social spaces are reflected on users of these platforms. Despite sharing a set pallet of possible social media use purposes, differences were found between demographics in terms of activity, popularity and links to the offline setting. Here, distinctions were made between general technology use trends such as social media use, primary digital divides in terms of access issues, and secondary digital divides in terms of use purpose and social media benefit inequality.

Notably, the growth patterns of social media use illustrated key changes in the Internet use landscape that open new areas of research into the reasons behind drastic differences in technology adoption rates among various age groups, for example. A general assumption in ICT research holds that the observed differences between population groups seem to even out over time. Our findings suggest that this does not always reflect reality or at least it has not happened yet in terms of different social media use purposes. Once formed, differences in use can be fairly permanent, even examining the rapidly changing social media use purposes. In this sense, differences in social media use seem to 
reflect primarily inequalities in offline surroundings. This means that to solve the problems of uneven distribution of societal benefits gained from social media use, inequality issues, such as inequality in participation for example, need to be solved first in societies in general.

Indeed, our findings link to past and more recent work: first, in terms of digital divides, by illustrating a convergence through higher registered online users and second, by illustrating the divergence stemming from use purpose differences. As such, newer divisions persist within the convergence zone of past inequality. Given these findings, cross-national comparisons that cover the trends in both advanced and emerging information societies in terms of overall access and use purpose divergence among population groups should be especially encouraged in future research.

Acknowledgements Open access funding provided by University of Turku (UTU) including Turku University Central Hospital.

Open Access This article is distributed under the terms of the Creative Commons Attribution 4.0 International License (http://creativeco mmons.org/licenses/by/4.0/), which permits unrestricted use, distribution, and reproduction in any medium, provided you give appropriate credit to the original author(s) and the source, provide a link to the Creative Commons license, and indicate if changes were made.

\section{References}

1. Bennett, W.L.: The personalization of politics: political identity, social media, and changing patterns of participation. Ann. Am. Acad. Political Soc. Sci. 644(1), 20-39 (2012). https://doi. org/10.1177/0002716212451428

2. Benson, V., Morgan, S., Filippaios, F.: Social career management: social media and employability skills gap. Comput. Hum. Behav. 30, 519-525 (2014). https://doi.org/10.1016/j.chb.2013.06.015

3. Campbell, C.: I shop therefore I know that I am: the metaphysical basis of modern consumerism. In: Ekström, K.M., Brembeck, H. (eds.) Elusive Consumption, pp. 27-44. Berg, Oxford (2004)

4. Castells, M.: Communication Power. Oxford University Press, Oxford (2009)

5. Correa, T., Hinsley, A.W., De Zuniga, H.G.: Who interacts on the web? The intersection of users' personality and social media use. Comput. Hum. Behav. 26(2), 247-253 (2010). https://doi. org/10.1016/j.chb.2009.09.003

6. DeLeeuw, E.D.: Mixed-mode: past, present, and future. Surv. Res. Methods 12(2), 75-89 (2018)

7. DiMaggio, P., Hargittai, E.: From the 'digital divide 'to 'digital inequality': studying internet use as penetration increases, working paper. In: Princeton: Center for Arts and Cultural Policy Studies, , vol. 4(1), pp. 4-21. Woodrow Wilson School, Princeton University, Princeton (2001)

8. DiMaggio, P., Hargittai, E., Neuman, W.R., Robinson, J.P.: Social implications of the Internet. Ann. Rev. Sociol. 27(1), 307-336 (2001). https://doi.org/10.1146/annurev.soc.27.1.307

9. Eastin, M.S.: Diffusion of e-commerce: an analysis of the adoption of four e-commerce activities. Telemat. Inform. 19(3), 251-267 (2002). https://doi.org/10.1016/S0736-5853(01)00005-3

10. Eurostat, (2017). Digital Economy and Society. Main tables. Retreived at: http://ec.europa.eu/eurostat/web/digital-economyand-society/data/main-tables
11. Floridi, L.: Mature information societies-A matter of expectations. Philos. Technol. 29(1), 1-4 (2016). https://doi.org/10.1007/ s13347-016-0214-6

12. Go, E., You, K.H.: But not all social media are the same: analyzing organizations' social media usage patterns. Telemat. Inform. 33(1), 176-186 (2016). https://doi.org/10.1016/j.tele.2015.06.016

13. Granovetter, M.S.: The strength of weak ties. Am. J. Sociol. 78(6), 1360-1380 (1973). https://doi.org/10.1016/B978-0-12-44245 $0-0.50025-0$

14. Greenwood, S., Perrin, A., Duggan, M.: Social Media Update 2016. Pew Research Center. http://www.pewinterne t.org/2016/11/11/social-media-update-2016/\#. Accessed 20 Mar 2018

15. Hargittai, E.: Second-Level Digital Divide: Mapping Differences in People's Online Skills. arXiv: arXiv:cs/0109068 (2001)

16. Hargittai, E., Hsieh, Y.L.P.: Predictors and consequences of differentiated practices on social network sites. Inform. Commun. Soc. 13(4), 515-536 (2010). https://doi.org/10.1080/1369118100 3639866

17. Hedman, U., Djerf-Pierre, M.: The social journalist: embracing the social media life or creating a new digital divide? Digit. Journal. 1(3), 368-385 (2013). https://doi.org/10.1080/21670 811.2013.776804

18. Hogan, B.: The presentation of self in the age of social media: distinguishing performances and exhibitions online. Bull. Sci. Technol. Soc. 30(6), 377-386 (2010). https://doi.org/10.1177/02704 67610385893

19. Holt, K., Shehata, A., Strömbäck, J., Ljungberg, E.: Age and the effects of news media attention and social media use on political interest and participation: do social media function as leveller? Eur. J. Commun. 28(1), 19-34 (2013). https://doi. org/10.1177/0267323112465369

20. Jin, S.A.A., Phua, J.: Following celebrities' tweets about brands: the impact of Twitter-based electronic word-of-mouth on consumers' source credibility perception, buying intention, and social identification with celebrities. J. Advert. 43(2), 181-195 (2014). https://doi.org/10.1080/00913367.2013.827606

21. Kaplan, A.M., Haenlein, M.: Users of the world, unite! The challenges and opportunities of Social Media. Bus. Horizon. 53(1), 59-68 (2010). https://doi.org/10.1016/j.bushor.2009.09.003

22. Kaplan, A.M., Haenlein, M.: Two hearts in three-quarter time: How to waltz the social media/viral marketing dance. Bus. Horizon. 54(3), 253-263 (2011). https://doi.org/10.1016/j.busho r.2011.01.006

23. Karlson, K.B., Holm, A., Breen, R.: Comparing regression coefficients between same-sample nested models using logit and probit: a new method. Sociol. Methodol. 42(1), 286-313 (2012). https:// doi.org/10.1177/0081175012444861

24. Keipi, T., Koiranen, I., Koivula, A., Räsänen, P.: Assessing the social media landscape: online relational use-purposes and life satisfaction among Finns. First Monday (2017). https://doi. org/10.5210/fm.v23i1.8128

25. Koivula A., Keipi T., Koiranen I., Räsänen P.: A middle-aged social internet with a millennial exodus? Changes in identifications with online communities between 2009 and 2017 in Finland. In: Meiselwitz G. (eds) Social Computing and Social Media. User Experience and Behavior. SCSM 2018. Lecture Notes in Computer Science, vol. 10913. Springer, Cham (2018)

26. Kraaykamp, G., Nieuwbeerta, P.: Parental background and lifestyle differentiation in Eastern Europe: social, political, and cultural intergenerational transmission in five former socialist societies. Soc. Sci. Res. 29(1), 92-122 (2000). https://doi.org/10.1006/ ssre.1999.0655

27. Lenhart, A., Purcell, K., Smith, A., Zickuhr, K.: Social media \& mobile internet use among teens and young adults. Millennials. 
Pew Internet and American Life Project. https://files.eric.ed.gov/ fulltext/ED525056.pdf. Accessed 20 Mar 2018

28. Lenhart, A., Duggan, M., Perrin, A., Stepler, R., Rainie, H., \& Parker, K.: Teens, social media \& technology overview 2015. Pew Research Center [Internet \& American Life Project]. http:// www.pewinternet.org/2015/04/09/teens-social-media-technology -2015/. Accessed 20 Mar 2018

29. Lindblom, T., Räsänen, P.: Between class and status? Examining the digital divide in Finland, the United Kingdom, and Greece. Inf. Soc. 33(3), 147-158 (2017). https://doi.org/10.1080/01972 243.2017.1294124

30. Livingstone, S., Haddon, L., Görzig, A., Ólafsson, K.: Risks and safety on the internet: The perspective of European children. Full Findings. EU Kids Online, LSE, London (2011)

31. Miller, D., Costa, E., Haynes, N., McDonald, T., Nicolescu, R., Sinanan, J., Spyer, J., Venkatraman, S., Wang, X.: How the World Changed Social Media. UCL Press, London (2016)

32. Napoli, P.M.: Audience Evolution: New Technologies and the Transformation of Media Audiences. Columbia University Press, New York (2011)

33. Näsi, M., Räsänen, P., Sarpila, O.: ICT activity in later life: internet use and leisure activities amongst senior citizens in Finland. Eur. J. Ageing 9(2), 169-176 (2012). https://doi.org/10.1007/ s10433-011-0210-8

34. Norris, P.: Digital Divide: Civic Engagement, Information Poverty, and the Internet Worldwide. Cambridge University Press, Cambridge (2001)

35. Novo-Corti, I., Varela-Candamio, L., García-Álvarez, M.T.: Breaking the walls of social exclusion of women rural by means of ICTs: The case of 'digital divides' in Galician. Comput Hum Behav 30, 497-507 (2014)

36. Official Statistics of Finland (OSF).: Use of Information and Communications Technology by Individuals [e-publication]. ISSN=2341-8710. Helsinki: Statistics Finland [referred: 14. 3. 2018]. http://www.stat.fi/til/sutivi/index_en.html (2018)

37. Panteli, N., Marder, B.: Constructing and enacting normality online across generations: the case of social networking sites. Inf. Technol. People 30(2), 282-300 (2017). https://doi.org/10.1108/ ITP-06-2015-0134

38. Perrin, A.: Social Networking Usage: 2005-2015. Pew Research Center. October 2015. http://www.pewinterne t.org/2015/10/08/2015/Social-Networking-Usage-2005-2015/ (2015)

39. Räsänen, P.: Consumption disparities in information society: comparing the traditional and digital divides in Finland. Int. J. Sociol. Soc. Policy 26(1/2), 48-62 (2006). https://doi.org/10.1108/01443 330610644425

40. Räsänen, P., Koiranen, I.: Changing patterns of ICT use in Finland: the senior citizens' perspective. In: Zhou, J., Salvendy, G. (eds.): Human Aspects of IT of the Aged Population. Design for Aging. Second International Conference, ITAP 2016, Proceedings, Part I (Volume 9754 of the series Lecture Notes in Computer Science), pp. 226-237. Springer, Switzerland, (2016)

41. Rogers, E.M.: Diffusion of Innovations. Free Press, New York (1995)

42. Scaramuzzino, G., Scaramuzzino, R.: The weapon of a new generation? Swedish Civil Society Organizations' use of social media to influence politics. J. Inf. Technol. Politics 14(1), 46-61 (2017). https://doi.org/10.1080/19331681.2016.1276501
43. Schradie, J.: The digital production gap: The digital divide and Web 2.0 collide. Poetics 39(2), 145-168 (2011). https://doi. org/10.1016/j.poetic.2011.02.003

44. Segerberg, A., Bennett, W.L.: Social media and the organization of collective action: using Twitter to explore the ecologies of two climate change protests. Commun. Rev. 14(3), 197-215 (2011). https://doi.org/10.1080/10714421.2011.597250

45. Selwyn, N., Gorard, S., Furlong, J., Madden, L.: Older adults' use of information and communications technology in everyday life. Ageing Soc. 23(5), 561-582 (2003). https://doi.org/10.1017/ S0144686X03001302

46. Sheldon, P., Bryant, K.: Instagram: motives for its use and relationship to narcissism and contextual age. Comput. Hum. Behav. 58, 89-97 (2016). https://doi.org/10.1016/j.chb.2015.12.059

47. Siren, A., Knudsen, S.G.: Older adults and the emerging digital service delivery. A mixed methods study on Information and communications technology use, skills and attitudes. J. Aging Soc. Policy 29(1), 35-50 (2017)

48. van Deursen, A.J., Helsper, E.J.: The third-level digital divide: Who benefits most from being online? In: Communication and Information Technologies Annual, pp. 29-52. Emerald Group Publishing Limited, Bingley (2015)

49. van Deursen, A., van Dijk, J.: Internet skills and the digital divide. New Media Soc. 13(6), 893-911 (2011). https://doi. org/10.1177/1461444810386774

50. van Deursen, A.J., van Dijk, J.A.: The digital divide shifts to differences in usage. New Media Soc. 16(3), 507-526 (2014). https ://doi.org/10.1177/1461444813487959

51. Van Dijck, J., Poell, T.: Understanding social media logic. Media Commun. 1(1), 2-14 (2013). https://doi.org/10.17645/mac. v1i1.70

52. van Dijk, J.A.: The Deepening Divide: Inequality in the Information Society. Sage Publications, London (2005)

53. Vicente, M.R., López, A.J.: Assessing the regional digital divide across the European Union-27. Telecommun. Policy 35(3), 220 237 (2011). https://doi.org/10.1016/j.telpol.2010.12.013

54. Weeks, B.E., Ardèvol-Abreu, A., Gil de Zúñiga, H.: Online influence? Social media use, opinion leadership, and political persuasion. Int. J. Publ. Opin. Res. 29(2), 214-239 (2017). https://doi. org/10.1093/ijpor/edv050

55. Wei, L., Hindman, D.B.: Does the digital divide matter more? Comparing the effects of new media and old media use on the education-based knowledge gap. Mass Commun. Soc. 14(2), 216-235 (2011). https://doi.org/10.1080/15205431003642707

56. Weis, A.H.: Commercialization of the internet. Internet Res. 20(4), 420-435 (2010). https://doi.org/10.1108/106622410110594 53

57. Wellman, B., Quan-Haase, A., Boase, J., Chen, W., Hampton, K., Díaz, I., Miyata, K.: The social affordances of the Internet for networked individualism. J. Comput. Med. Commun. (2003). https://doi.org/10.1111/j.1083-6101.2003.tb00216.x

Publisher's Note Springer Nature remains neutral with regard to jurisdictional claims in published maps and institutional affiliations. 